\title{
Arthroscopy in the diagnosis of chondromalacia patellae
}

\author{
IAN J. LESLIE AND GEORGE BENTLEY
}

From the Nuffield Department of Orthopaedic Surgery, Nuffield Orthopaedic Centre, Oxford and the Depasytment of Orthopaedic Surgery, University of Liverpool

SUMmARY Chondromalacia patellae is difficult to diagnose clinically with accuracy. In order $\mathbb{R}_{0}$ clarify the relevant symptoms and signs, 78 patients presenting with a clinical diagnosis of chond $\overline{0}-$ malacia were examined by arthroscopy. In $49 \%$ of the knees no abnormalities were found. Pf senting symptoms were similar in the normal and abnormal groups. Physical signs were mope helpful in diagnosis and it is considered that the presence of an effusion, quadriceps wasting, agd patello-femoral crepitus are the most important clinical findings in the diagnosis of chondromalacia patellae. The arthroscope is a valuable instrument in establishing the diagnosis of chondromalacia patellae especially in the teenage female.

Chondromalacia patellae, or softening of the articular cartilage of the patella, manifested by pain in the patello-femoral joint, is a common disorder affecting adolescents and young adults. Büdinger (1906) first described fissures occuring in the articular cartilage of the patella and the term 'chondromalacia patellae' was introduced by König (1924) and Aleman (1927).

The true incidence of this disease is unclear. Anderson (1944) reported an incidence of $20 \%$ in 50 arthrotomies, Soto-Hall (1945) $18.5 \%$ in 65 arthrotomies, and Cave et al. (1945) $7 \%$ in 124 arthrotomies. Wiles et al. (1956) stated that it is present in $50 \%$ of the population by the age of 30 . However, the diagnosis of the majority is made on the clinical findings alone. Of the 771 diagnosed at the Nuffield Orthopaedic Centre between 1968 and 1972 only 229 came to arthrotomy for persistent and severe symptoms and in 8 of these there was no abnormality demonstrated at operation. The incidence of cartilage softening or fibrillation in the remaining 542 is therefore unknown. The diagnosis is difficult to make clinically and several authors observed that chondromalacia patellae may produce varied symptoms and signs which confuse the clinician and lead to a wrong diagnosis with sometimes incorrect treatment, or that it is diagnosed by a process of elimination (Devas, 1960; Smillie, 1974).

Accepted for publication January 20, 1978

Correspondence to Mr I. J. Leslie, Department of Orthopaedic Surgery, University of Liverpool, PO Box 147, Liverpool L69 3BX.
The 'look and see' arthrotomy is not advocated because of the slight but definite risk of infection in a normal joint and deep venous thrombosis, file period of 6 weeks or more required for recovery muscle tone and function after operation.

The arthroscope provides an easy method sof examining the interior of the knee joint. It provi霍s a good view of the patello-femoral joint (Casscells, 1971) and is associated with a very low morbidity (Jackson and Abe, 1972). The role of the arthroscopbe in the diagnosis of knee joint problems has been reported many times (Burman et al., 1934; Watanabe and Takeda, 1960; Henry, 1972; Jackson and A $\overrightarrow{\mathrm{B} e}$, 1972; Gallannaugh, 1973; Dashefsky, 1974; Dandy and Jackson, 1975) and it is interesting to note that the diagnosis of chondromalacia patellae was mate only 39 times in the 700 cases reported in the series, an incidence of $5.5 \%$

Clinical diagnostic criteria for chondromalaçia patellae have been stated by Wiles et al. (1956), Devas (1960), and Robinson and Darracott (1970). These criteria should assist the clinician to make a positive diagnosis of chondromalacia and to differentiate it from other conditions occurring in the knee, such as a torn medial meniscus. However, most surgeons have found a poor correlation between the severity of the disease present at arthrotony and the type and severity of the symptoms physical signs. In fact the articular cartilage may log $\mathrm{k}$ and feel normal at operation even after a positive clinical diagnosis has been made.

In order to investigate this difficulty, a prospect 
trial was set up to examine by arthroscopy all knees in which a clinical diagnosis of chondromalacia was made and to correlate the changes found on the undersurface of the patella with the symptoms, signs and clinical diagnosis.

\section{Patients}

Out-patients who were seen in the professorial unit of the Nuffield Orthopaedic Centre and in whom a clinical diagnosis of chondromalacia patellae was made were entered into the trial. Diagnosis was made in 78 patients affecting 78 knees in the period April 1973-April 1976. Eighty per cent were referred to the clinic by general practitioners, $17 \%$ from other orthopaedic surgeons and 3\% from the accident service. All patients had experienced symptoms for at least 3 months.

Arthroscopy was performed in all these patients. The age range was from 10 years to 40 years with a mean of 21.9 years. There were 52 females and 26 males (ratio 2:1). The right knee was involved in 48 and left in $30(1 \cdot 6: 1)$.

\section{CRITERIA FOR DIAGNOSIS}

Clinical diagnosis in this study was based on the symptoms and physical findings as described by Wiles et al. (1956) and Robinson and Darracott (1970).

The symptoms are described as a retro-patellar pain or deep-seated ache, worse when the knee is extended against resistance and aggravated by climbing stairs, sitting with knees flexed for any length of time, and rising from a sitting position. A sense of insecurity may be felt on weight bearing and a momentary catch may be experienced, but locking is not a feature. At least 2 of the following 4 physical signs were necessary for a positive diagnosis. (1) Pain when the patella is compressed firmly against the femoral condyles with the knee in full extension. (2) Tenderness of the postero-medial edge of the patella when the patella is pushed medially away from the femoral condyles. (3) Pain when the knee is extended against resistance. (4) Pain when the patient, with extended knee, statically contracts his quadriceps against resistance of the examiner's finger and thumb placed against the upper border of the patella.

The duration of symptoms, history of trauma, site of pain, factors aggravating the pain, swelling, 'giving way', and 'locking' were recorded. The physical signs recorded were tenderness at other sites, effusion, quadriceps wasting measured $5 \mathrm{~cm}$ above the superior border of the patella, palpable retropatellar crepitus, and the flexion-extension range of motion of the knee.
Antero-posterior and lateral radiographs were taken, as well as tangential views of both patellae with the knee in $30^{\circ}$ and $60^{\circ}$ of flexion in order to exclude any evidence of lateral subluxation (Ficat, 1973).

\section{ARTHROSCOPY}

The patients were admitted on the day before arthroscopy. General anaesthetic was used to give full relaxation of the knee and a pneumatic tourniquet applied on the side concerned. The procedures were performed by normal sterile technique in a conventional operating theatre. The Storz arthroscope was used and the examination was carried out through a lateral stab incision $1 \mathrm{~cm}$ lateral to the patellar tendon and $1 \mathrm{~cm}$ above the lateral joint line. This was low enough to obtain a good view over the undersurface of the patella. The medial aspect of the patella was examined by tilting the bone externally during the viewing procedure. The joint was filled with saline via the arthroscope before viewing and all areas of the joint including the femoral condyle, menisci and cruciate ligaments were examined to exclude any other cause for the symptoms. Any abnormal areas of the patella were photographed. A relationship between the arthroscopic appearances and the extent of patellar cartilage damage at arthrotomy had been established and this made grading of the changes possible.

Chondromalacia was graded according to a modification (Bentley, 1970) of the classification of Outerbridge (1961), where grade $I$ is a localised softening, swelling, or fibrillation of the articular cartilage in an area of $0.5 \mathrm{cms}$ or less (Fig. 1).

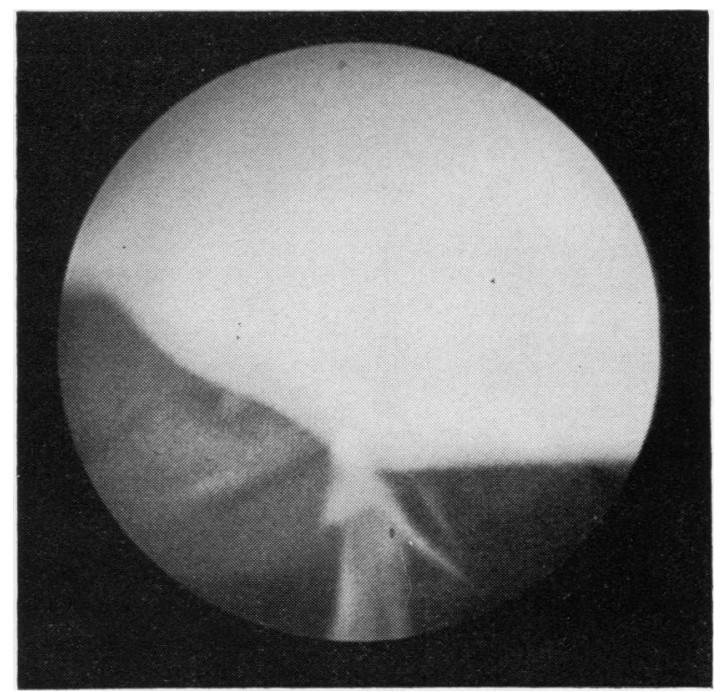

Fig. 1 Grade I chondromalacia. 
Grade II is fragmentation and fissuring in an area $1.3 \mathrm{~cm}$ or less in diameter (Fig. 2). Grade III is fragmentation and fissuring in an area of more than $1.3 \mathrm{~cm}$ in diameter (Fig. 3). Grade IV is erosion of articular cartilage down to subchondral bone.

At the end of the procedure the fluid was emptied from the joint and the wound closed with one skin suture. An adhesive dressing was applied as well as a compression bandage of wool and crepe which the patients retained for 48 hours. The patients commenced walking and were discharged on the following day. Conservative therapy was instituted in those with chondromalacia and definitive surgery

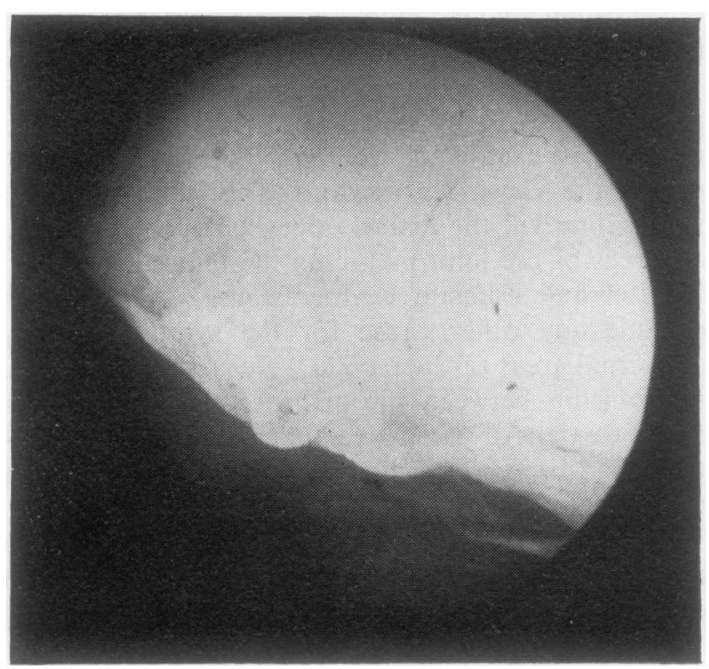

Fig. 2 Grade II chondromalacia.

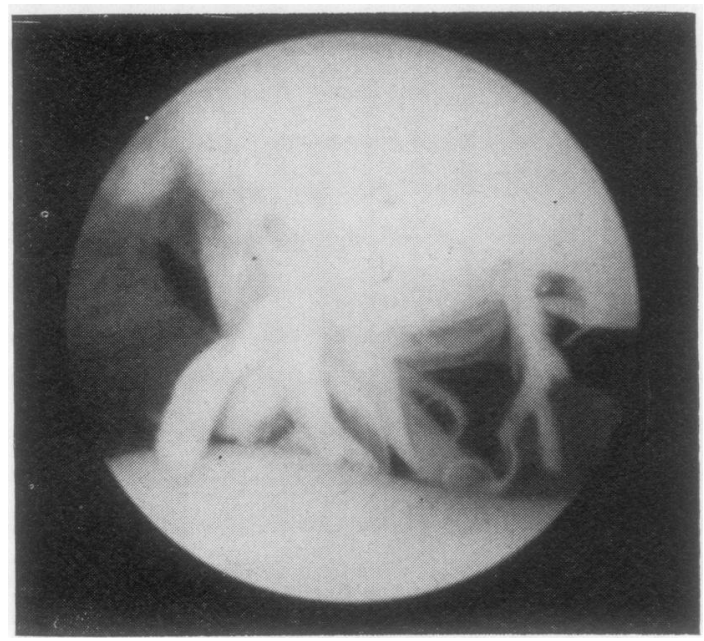

Fig. 3 Grade III chondromalacia. if necessary deferred for at least 3 months. Thos
with normal findings were not discharged bu reviewed in out-patient clinics at regular intervals

Results

ACCURACY OF CLINICAL DiAgNosis (Table 1) Seventy-eight knees in which a definite diagnosis? of chondromalacia had been made were examine by arthroscopy. In $40(51 \%)$ the diagnosis wa\& confirmed. However, in the remaining $38(49 \%)$ the. articular cartilage of the patella and femoral con= dyles was smooth, glistening with no loss of lustre $\vec{\omega}$ and no evidence of softening. No other abnormality was found and therefore the cause of the pain in this group is not clear and remains speculativew In 2 patients with a confirmed diagnosis of chondromalacia a torn medial meniscus was also seen. The low incidence of other abnormalities is considered tक be due to the stringent positive criteria for diagnosiso

Of the 40 patients who had chondromalacia, 12 $(28 \%)$ had Grade I, 10 (25\%) had grade II, and 19 $(47 \%)$ had grade III No patient had grade IV (Table 2).

FACTORS INFLUENCING THE RESULTS

\section{Duration of symptoms}

Symptoms in those with chondromalacia had present for a period ranging from 4 months to years with a mean of 23.9 months. In the normas group the period ranged from 3 months to 10 years with a mean of $27 \cdot 1$ months. The difference is no $\$$ significant. It is interesting to note that even if some patients who had symptoms for as long as 19 years, no abnormality of articular cartilage could be found yet some patients with pain for only 4 monthe had chondromalacia at arthroscopy. The average

Table 1 Findings at arthroscopy

\begin{tabular}{llll}
\hline Findings & No. & $(\%)$ \\
\hline Normal & 38 & $(49)$ & \\
Chondromalacia & 40 & $(51)$ \\
Total & 78 & $(100)$ & 7 \\
\hline
\end{tabular}

Table 2 Severity of disease in those with chondromalacia

\begin{tabular}{|c|c|c|}
\hline Outerbridge grading & No. & $(\%)$ \\
\hline $\begin{array}{l}\text { I } \\
\text { II } \\
\text { III }\end{array}$ & $\begin{array}{r}11 \\
10 \\
19 \\
0\end{array}$ & $\begin{array}{l}(27 \cdot 5) \\
(25) \\
(47 \cdot 5) \\
(0)\end{array}$ \\
\hline Total & 40 & (100) \\
\hline
\end{tabular}


duration of symptoms for those with grade I chondromalacia was 24 months, with grade II 27 months, and for those with grade III only 20 months.

\section{Knee trauma (Table 3)}

Ten $(26 \%)$ of the patients with normal appearances had attributed their symptoms to trauma, 7 being direct and 3 indirect, such as twisting injury. Fifteen $(37 \%)$ of those patients with chondromalacia patellae also gave a history of trauma. In 8 of these it was direct and in 7 indirect. These differences are not significant.

\section{Sex (Tables 4 and 5)}

There were twice as many females as males, however the proportion of normal findings and the distribution of the various grades of chondromalacia were

Table 3 Incidence of history of trauma

\begin{tabular}{llllr}
\hline $\begin{array}{l}\text { Confirmed } \\
\text { diagnosis }\end{array}$ & $\begin{array}{l}\text { Direct } \\
\text { trauma }\end{array}$ & $\begin{array}{l}\text { Indirect } \\
\text { trauma }\end{array}$ & $\begin{array}{l}\text { Total } \\
\text { with trauma }\end{array}$ & $\begin{array}{l}\text { Total } \\
\text { without trauma }\end{array}$ \\
\hline Normal & 7 & 3 & $10(26 \%)$ & $18(74 \%)$ \\
Chondromalacia & 8 & 7 & $15(37 \%)$ & $25(63 \%)$ \\
Grade I & 3 & 1 & $4(36 \%)$ & $7(64 \%)$ \\
Grade II & 2 & 2 & $4(40 \%)$ & $6(60 \%)$ \\
Grade III & 3 & 4 & $7(37 \%)$ & $12(63 \%)$ \\
\hline
\end{tabular}

Table 4 Findings at arthroscopy in males and females

\begin{tabular}{lll}
\hline & Females & Males \\
\hline Normal & $25(48 \%)$ & $13(50 \%)$ \\
Chondromalacia & $27(52 \%)$ & $13(50 \%)$ \\
Total & $52(100 \%)$ & $26(100 \%)$ \\
\hline
\end{tabular}

Table 5 Severity of chondromalacia in males and females

\begin{tabular}{lcc}
\hline Grade & Females & Males \\
\hline I & $8(30 \%)$ & $3(23 \%)$ \\
II & $6(22 \%)$ & $4(31 \%)$ \\
III & $13(48 \%)$ & $6(46 \%)$ \\
Total & $27(100 \%)$ & $13(100 \%)$ \\
\hline
\end{tabular}

similar for each sex. However, age within sex did have a definite influence.

Age

The mean age of patients presenting with a clinical diagnosis of chondromalacia was 21.9 years with a range from 10 to 40 years. Females had a mean age of 21.4 years and males 23 years.

The females with normal findings at arthroscopy had a mean age of 17.7 years, and those with a definite diagnosis of chondromalacia had a mean age of 24.7 years. This difference is significant (difference between means is 4 times the standard error of the mean). In males there was no significant difference and the mean age for normal findings was higher than in the females.

In females the severity of the disease increased with age, in that the mean age for females with grade I was 20.4 years, with grade II 24.3 years, with grade III 27.7 years. The progression did not occur in males (Table 6, Fig. 4).

If the patients are grouped according to age into those under 20,20 to 29 , and 30 to 40 years then it is seen that the females under 20 have a high incidence of normal findings (Table 7 and Fig. 5) whereas those over 30 have a low incidence. However in males there is little variation between the age groups (Table 8 and Fig. 5).

Table 6 Relationship of age to arthroscopic findings. Mean age of patients with normal findings and those with chondromalacia

\begin{tabular}{llll}
\hline & \multicolumn{2}{l}{ Mean age (years) } & \\
\cline { 2 - 2 } Arthroscopic findings & Females & Males \\
\hline Normal & $17 \cdot 7$ & $22 \cdot 5$ \\
Chondromalacia & $24 \cdot 7$ & $23 \cdot 5$ \\
Grade I & $20 \cdot 4$ & $22 \cdot 3$ \\
Grade II & $24 \cdot 3$ & $24 \cdot 0$ \\
Grade III & $27 \cdot 7$ & $23 \cdot 8$ \\
Overall mean age & $21 \cdot 4$ & 23 \\
\hline
\end{tabular}

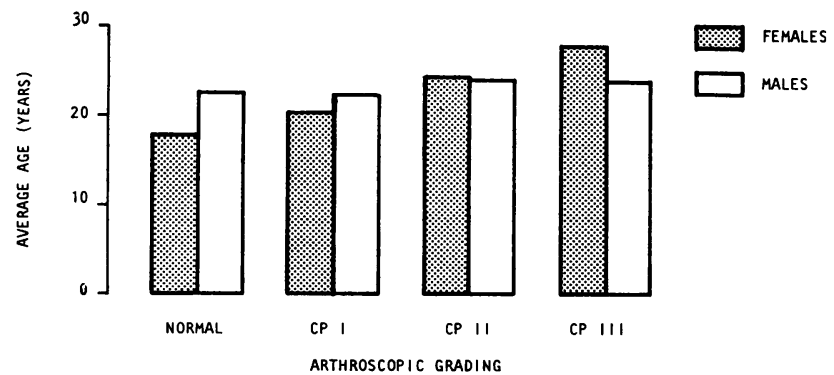

Fig. 4 The average age increases as the severity of the disease increases in females. However, in males the average age remains about constant. 
Table 7 Relationship of age to arthroscopic findings. The incidence of normal findings for each age group in females

\begin{tabular}{lcc}
\hline Age (years) & Normal & Chondromalacia \\
\hline $0-19$ & $19(76 \%)$ & $11(41 \%)$ \\
$20-29$ & $5(20 \%)$ & $7(26 \%)$ \\
$30-40$ & $1(4 \%)$ & $9(33 \%)$ \\
Totals & $25(100 \%)$ & $27(100 \%)$ \\
\hline
\end{tabular}

Table 8 Relationship of age to arthroscopic findings. The incidence of normal findings for each age group in males

\begin{tabular}{lcc}
\hline Age (years) & Normal & Chondromalacia \\
\hline $0-19$ & $6(46 \%)$ & $5(38 \%)$ \\
$20-29$ & $4(31 \%)$ & $4(31 \%)$ \\
$30-40$ & $3(23 \%)$ & $4(31 \%)$ \\
Totals & $13(100 \%)$ & $13(100 \%)$ \\
\hline
\end{tabular}

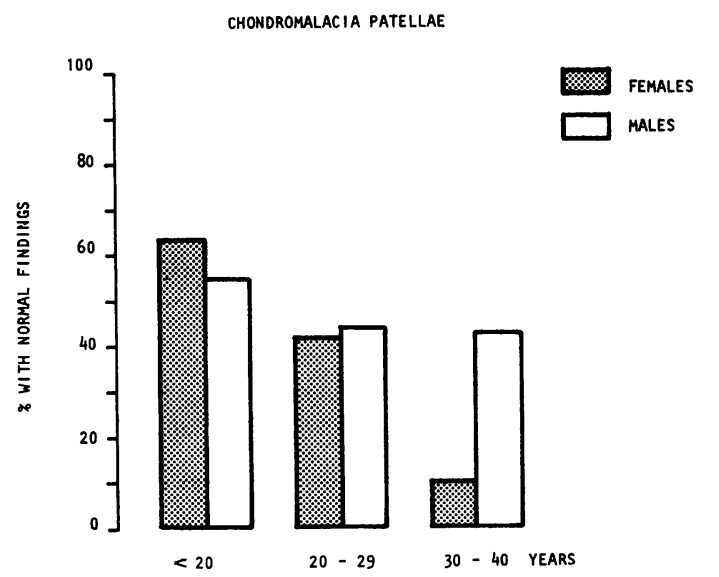

Fig. 5 The percentage of normal findings decreased as females became older. However, males had a more equal distribution in the three age groups.

This has confirmed a clinical impression that patello-femoral pain is complained of often by teenage females without evidence of disease of the patella.

\section{SYMPTOMS INDICATIVE OF CHONDROMALACIA PATELLAE}

The symptoms in those patients with chondromalacia and in those with normal findings are shown in Table 9. All patients complained of retropatellar pain aggravated mostly by activity and many had given up sport because of this. In those patients with definite chondromalacia patellae, the pain was felt on ascending or descending stairs by $42 \%$, on sitting for prolonged periods by $21 \%$ and on kneeling or squatting by $9 \cdot 7 \%$. 'Giving way' was noticed $26 \%$ and swelling by $42 \%$.

The incidence of these symptoms in patients with confirmed chondromalacia was not significant different from those patients with normal finding at arthroscopy. No symptom was specific for the diagnosis of chondromalacia patellae.

\section{PHYSICAL SIGNS INDICATIVE OF}

CHONDROMALACIA PATELLAE

At examination of the joints the following obser vations were recorded. (1) Tenderness on palpation on the undersurface of the patella medially (Wiles et al., 1956; Devas, 1960). (2) Quadriceps wasting $\$$ greater than $2 \mathrm{~cm}$ in circumference compared wit the opposite normal side at a point $5 \mathrm{~cm}$ above thio patella. (3) Effusion into the joint. (4) Palpables crepitus from the patello-femoral joint compari ment. (5) Range of flexion-extension in the knee joint. (6) Medial joint line tenderness.

All but one patient in each group had a full range of motion so this is not recorded. All patients has retropatellar tenderness as this was a prerequisit for entry into the trial, but this was not a helpfit physical sign in distinguishing those patients who had a macroscopical lesion on the undersurface of the patella.

The 3 physical signs which were most helofil were presence of an effusion, palpable retropatefor crepitus, and quadriceps wasting (Table 10). Th differences are significant as indicated.

Effusion was present in $22 \%$ of those with chondro⿱ malacia but did not occur in those with norma findings $(P<0.01)$. Crepitus was palpable in 58 \% of those with chondromalacia compared with $23 \%$

Table 9 Symptoms in relationship to arthroscopy findings. Those with chondromalacia experience similar symptoms to those with no abnormality detected

\begin{tabular}{lcr}
\hline Symptom & Chondromalacia & Normal \\
\hline Pain on activity & $36(87 \%)$ & $35(87 \%)$ \\
Pain on stairs & $17(42 \%)$ & $15(37 \%)$ \\
Pain on sitting & $9(21 \%)$ & $11(27 \%$ \\
Pain on squatting & $4(9.7 \%)$ & $5(12 \%$ \\
Swelling & $17(42 \%)$ & $9(22 \%)$ \\
Giving way & $11(26 \%)$ & $12(30 \%)$ \\
Catching & $6(14 \%)$ & $2(5 \%)$ \\
\hline
\end{tabular}

Table 10 Physical signs in relationship to arthroscopy findings

\begin{tabular}{|c|c|c|c|}
\hline Physical signs & Chondromalacia & Normals & 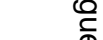 \\
\hline $\begin{array}{l}\text { Patello-femoral crepitus } \\
\text { Quadriceps wasting } \\
\text { Effusion } \\
\text { Medial joint line tenderness }\end{array}$ & $\begin{array}{l}24(58 \%) \\
18(45 \%) \\
9(23 \%) \\
4(10 \%)\end{array}$ & $\begin{array}{l}9(24 \%) \\
7(17 \%) \\
0 \\
4(10 \%)\end{array}$ & $\begin{array}{l}P<0.09 \\
P<0.05 \\
P<0.05\end{array}$ \\
\hline
\end{tabular}


in those with normal findings $(\mathrm{P}<0.02)$. Quadriceps were wasted in $45 \%$ of those with chondromalacia compared with $17 \%$ of those with no abnormality $(\mathrm{P}<0.05)$.

The relationship between the severity of chondromalacia and these significant physical signs is shown in Table 11. It is clear that those with grade III chondromalacia had more overt signs and in this series it did not exist without two or more of these physical findings, in addition to the clinical criteria of Robinson and Darracott (1970). The incidence of positive physical findings increased as the severity of chondromalacia increased.

A small proportion of patients had medial joint tenderness which was considered to be due to inflammation of the synovial membrane at the margins of the menisci. In 2 of these a lesion of the medial meniscus was found but both of these also had chondromalacia.

Radiological appearances in chondromalacia patellae No signs diagnostic of chondromalacia were found on the anteroposterior or lateral radiographs of the knee. Subluxation was assessed according to the method of Ficat (1973) by comparing the tangential views of the patella taken with the knee flexed at $30^{\circ}$ and $60^{\circ}$. Lateral subluxation was uncommon and found in only 2 of the normal knees and 6 of those with chondromalacia.

\section{Complication of arthroscopy}

No complications were experienced.

\section{FOLLOW UP}

The follow up period ranged from 9 months to 2 years, and consisted of that performed at the routine review at the outpatient clinic and also a postal questionnaire asking whether the retropatellar pain was better, the same or worse than at the time of the arthroscopy. Fifty-six $(72 \%)$ replies to the questionnaire were received from the 78 patients. Sixty-three per cent of those who had had normal findings replied and $80 \%$ of those who had a definite diagnosis of chrondromalacia replied.

Of the 24 who replied who had normal findings $58 \%$ said they were better, $34 \%$ the same, and $8 \%$

Table 11 Physical signs in relationship to severity of chondromalacia

\begin{tabular}{|c|c|c|c|}
\hline \multirow[b]{2}{*}{ Physical sign } & \multicolumn{2}{|c|}{ Chondromalacia } & \multirow[b]{2}{*}{ Grade III } \\
\hline & Grade I & Grade II & \\
\hline $\begin{array}{l}\text { Patello-femoral crepitus } \\
\text { Quadriceps wasting } \\
\text { Effusion }\end{array}$ & $\begin{array}{l}4(36 \%) \\
5(45 \%) \\
0(0 \%)\end{array}$ & $\begin{array}{l}5(50 \%) \\
4(40 \%) \\
2(20 \%)\end{array}$ & $\begin{array}{r}15(80 \%) \\
9(47 \%) \\
7(37 \%)\end{array}$ \\
\hline Total & 11 & 10 & 19 \\
\hline
\end{tabular}

were worse. Of the 32 who replied who had chondromalacia $66 \%$ said they were better, $16 \%$ the same and $18 \%$ worse. However, the results of those who had chondromalacia were coloured by the fact that 18 of the 32 patients had operations on the knee. Of the 18 who had an operation 13 were better, 1 the same, and 4 were worse.

\section{Discussion}

The arthroscopic examination of all patients with a clinical diagnosis of chondromalacia patellae has enabled us to determine which clinical symptoms and signs are the most important indicators of patellar cartilage damage. The clinical diagnosis was made on the criteria set out by various authors (Wiles et al., 1956; Robinson and Darracott, 1970). In each case the diagnosis was made positively and not by a process of elimination, which probably explains the low incidence of other findings such as a torn medial meniscus with which chondromalacia is often confused but which can be diagnosed accurately by arthroscopy (Cave et al., 1945; Wiles et al., 1956). A torn medial meniscus was found additionally in only 2 patients with chondromalacia patellae.

\section{CLINICAL DIAGNOSIS OF \\ CHONDROMALACIA PATELLAE}

\section{Symptoms}

The principal symptom of chondromalacia patellae is described as being of an aching character located in the retropatellar area, made worse by activity which loads specifically the patello-femoral joint, such as squatting and kneeling or sitting with knees flexed. Swelling of the joint, 'giving-way', and 'locking' are less common symptoms.

There was no variation between the two groups in the pattern of retropatellar pain, its site, or its aggravating factors. The reason for pain in chondromalacia patellae is unknown and it is interesting that the character of pain in both groups of patients appeared to be the same. Articular cartilage has no nerve endings and it has been suggested that the pain felt in the patella in this condition is due to alteration of blood supply of the patella associated with osteoporosis of the subchondral bone (Darracott and Vernon-Roberts, 1971). It was a notable feature in this survey that no abnormality of the patella was demonstrated on the anteroposterior, lateral, or tangential radiographs. We suggest that the pain is due to stimulation of nerve endings in subchondral bone by cathepsins released by damaged chondrocytes from the deep layers of the abnormal cartilage. Devas (1960) described the pain as being characteristically worse, not with exercise, but with 
rest, particularly after sitting still for any length of time. However, pain was aggravated by positions and movements of the knee which threw extra load on the patello-femoral joint. Thus pain was present with activity in $87 \%$ of our patients with chondromalacia patellae, on climbing stairs in $42 \%$, when sitting in a position with knees flexed for any length of time in $21 \%$, with squatting in $9.7 \%$ and at rest in bed in only $2 \%$. Interestingly the pain in the knees with no demonstrable abnormalities, was aggravated by the same factors and to an equal extent.

The cause of the pain in those patients in whom no abnormality was found is unknown.

Swelling of the joint and a sensation of locking occurred more commonly in patients with chondromalacia but 'giving way' occurred equally in both groups.

Our findings show that it is difficult if not impossible to separate, on the basis of the clinical history and symptoms, those patients with chondromalacia patellae from those with normal patellar cartilage.

\section{Physical signs}

Wiles et al. (1956) stated that a positive diagnosis of chondromalacia can be made by the physical signs, and with this we agree. However, they considered that the presence of pain on rubbing the patella on the underlying femoral condyles, together with tenderness behind the patella was diagnostic. Moreover, they stated that the presence of an effusion was of little diagnostic value and that patello-femoral crepitus was misleading. The present findings are different. Retropatellar tenderness was used as a criterion for diagnosis and $49 \%$ of the patients with this finding had normal knees. Much more important was the presence of an effusion which was never present in the normal knees. This difference is highly significant $(\mathrm{P}<0.01)$. Breakdown of the matrix of articular cartilage and release of small fragments into the joint produces direct inflammation of the synovial membrane (Chrisman et al., 1965) and hence the effusion, which is a most important diagnostic point. Retropatellar crepitus, due to increased friction in the patello-femoral joint caused by the fibrillated articular cartilage of the patella, occurred $2 \frac{1}{2}$ times more commonly in chondromalacia than in normals and this difference is significant also $(P<0.02)$. Quadriceps wasting occurring in response to an inflammed synovial membrane was present $2 \frac{1}{2}$ times more commonly in those with chondromalacia patallae than in those with normal knees. This difference is significant $(P<0.05)$. We consider that these three physical findings of effusion, quadriceps wasting, and retropatellar crepitus are most important in the diagnosis of chondromalacia patellae.
It is difficult to diagnose the severity of the diseasह by the history and physical findings but it is apparen? from this study that chondromalacia was not pres sent without at least one of the above physicat findings, in addition to the generally accepte criteria of Robinson and Darracott (1970).

\section{Influence of sex and age on diagnosis}

Thirty $(40 \%)$ of the patients were females under the age of 20 and of these only $37 \%$ had any abnormality demonstrable. By contrast, in 22 females over 20 chondromalacia was present in $91 \%$. There were fewer mis-diagnoses in the teenage male, with $54 \%$ of the 11 under the age of 20 and $53 \%$ of the 15 ove 20 having demonstrable abnormalities in the knee? These findings confirm the well-known difficulty of diagnosis in the teenage female and arthroscopy is oq great value in identifying those with no abnor mality in the knee so that treatment and sometime morbidity is not prolonged on the basis of an erron eous diagnosis and operation.

\section{Trauma as a cause of chondromalacia patellae}

The role of trauma in the aetiology of chondros malacia patellae has not been resolved. There is nơ doubt that stellate fractures of articular cartil\&ge can occur due to direct trauma as first demonstrakedo by John Hunter but the role of indirect twis injuries producing shearing stresses on the articuta cartilage and subsequent chondromalacia is nof fully established. It is interesting that in this stud\% only $37 \%$ reported a history of trauma to the knee and yet $26 \%$ of the normals described a traumatio onset.

\section{Follow-up progress}

The follow up of these patients gave reassurance that those diagnosed as normal did not get worse (excep for 1 female aged 14 and 1 male aged 22, neither of whom had sought further treatment.) There always the doubt raised that an abnormality waS missed by the arthroscope and this is quite real in inexperienced hands. However, one of us (G.B.) ha\& performed over 100 arthroscopies before the comp mencement of this trial and both of us were present at all these examinations. The follow-up of those whou had a diagnosis of chondromalacia is the subject of another paper.

It would seem that those who had normal findings have not progressed in that their symptoms have not become worse. However, this can only be sube stantiated by re-arthroscopy of all the normas patients, and this has not been done and it would only be justified if their symptoms had become worse.

.


Cause of pain in 'normal' knees

The reason for retropatellar pain in knees which appear normal at arthroscopy as yet is unexplained. It is unlikely that those patients who had retropatellar pain with normal findings at arthroscopy were just in the early stage of the disease and would later develop macroscopic evidence of chondromalacia, since the average duration of symptoms was 27 months ranging from 10 years to 3 months and one would have expected that those with such a long history would have developed changes especially when the average duration of symptoms of those with grade III chondromalacia was only 20 months.

\section{Conclusions}

Despite the fact that Wiles et al. (1956) stated that a positive clinical diagnosis of chondromalacia is nearly always correct, this study confirms that chondromalacia patellae is difficult to diagnose clinically. Symptoms are unreliable in diagnosis but the physical findings of joint effusion, quadriceps wasting, and retropatellar crepitus are the most valuable. It has been shown that positive diagnosis can be wrong in $49 \%$ of cases when the diagnosis is based on the previously described criteria. The diagnosis should be made with caution in the teenage female. No evidence was found in this survey to support the concept that chondromalacia is due to trauma. Arthroscopy increases the accuracy of diagnosis and is considered to be of definite value especially in excluding chondromalacia patellae in patients with persistent retropatellar pain.

We wish to thank Professor R. B. Duthie for advice and encouragement, also the Consultants of the Nuffield Orthopaedic Centre, Oxford who included some of their patients in the study. The manuscript was prepared by Miss Lorna Marshall. G. Bentley was supported by a grant (No. B28) from the Arthritis and Rheumatism Council.

\section{References}

Aleman, O. (1928). Chondromalacia posttraumatica patellae. Acta Chirgurgica Scandinavica, 63, 149-190.

Anderson, E. M. (1944). Arthrotomy of the knee: review of 50 cases. US Navy Medical Bulletin, 42, 1314-1316.
Bentley, G. (1970). Chondromalacia patellae. Journal of Bone and Joint Surgery, 52A, 221-232.

Büdinger, K. (1906). Über Ablösungen von Gelenkteilen und verwandte Progesse. Deutsche Zeitschrift für Chirurgie, 84, 311-365.

Burman, M. S., Finkelstein, H., and Mayer, L. (1934). Arthroscopy of the knee joint. Journal of Bone and Joint Surgery, 16, 255-268.

Casscells, S. W. (1971). Arthroscopy of the knee joint. Journal of Bone and Joint Surgery, 53A, 287-298.

Cave, E. F., Rowe, C. R., and Yee, L. B. K. (1945). Chondromalacia of the patella. Surgery, Gynaecology and Obstetrics, 81, 446-450.

Chrisman, O. D., Fessel, J. M., and Southwick, W. O. (1965). Experimental production of synovitis and marginal articular exostoses in the knee joints of dogs. Yale Journal of Biological Medicine, 37, 509-412.

Darracott, J., and Vernon-Roberts, B. (1971). The bony changes in chondromalacia patellae. Rheumatology and Physical Medicine, 11, 175-179.

Dandy, D. J., and Jackson, R. W. (1975). The impact of arthroscopy of the management of disorders of the knee. Journal of Bone and Joint Surgery, 57B, 346-348.

Dashefsky, J. H. (1974). Arthroscopy of the knee joint. New York State Journal of Medicine, 1049-1052.

Devas, M. B. (1960). Chondromalacia of the patella. Clinical Orthopaedics, 18, 54-61.

Ficat, P. (1973). Les Desequilibres Rotuliens de l'Hyperpression à l'Arthrose. Masson, Paris.

Gallannaugh, S. (1973). Arthroscopy of the knee joint. British Medical Journal, 3, 285-286.

Henry, A. (1972). Arthroscopy of the knee joint. Guys Hospital Reports, 121, 25-30.

Hunter, J. Specimen P. 961 in the descriptive catalogue of the pathological series in the Hunterian Museum, Part II.

Jackson, R. W., and Abe, I. (1974). The role of arthroscopy in the management of disorders of the knee. Journal of Bone and Joint Surgery, 54B, 310-322.

König, G. (1924). Mikroskipische Beobachtungen am Knorpelgewebe mit ultra-violettem Licht. Verhandlugen der Physikalisch-medizinishen Gesellschaft zu Wurzburg, 49, 160-162.

Outerbridge, R. E. (1961). The etiology of chondromalacia patellae. Journal of Bone and Joint Surgery, 43B, 752-757.

Robinson, A. R., and Darracott, J. (1970). Chrondromalacia patellae. Annals of Physical Medicine, 10, 286-290.

Smillie, I. S. (1974). Diseases of the Knee Joint. Churchill Livingstone: London.

Soto-Hall, R. (1945). Traumatic degeneration of the articular cartilage of the patella. Journal of Bone and Joint Surgery, 27, 426-431.

Wiles, P., Andrews, P. S., and Devas, M. B. (1956). Chondromalacia patellae. Journal of Bone and Joint Surgery, 38B, 95-113.

Watanabe, M., and Takeda, S. (1960). The No. 21 Arthroscope. Journal of the Japanese Orthopaedic Association, 34, 1041-1051. 